\title{
Metal mirror based VIS freeform telescope with smart alignment approach
}

\section{Matthias Beier $^{1 *}{ }^{*}$, Stefan Risse ${ }^{1}$, Wolfgang Holota ${ }^{2}$, Christoph Straif $^{3}$,Sebastian Fischer ${ }^{3}$,}

ICSO 2018, Session 4b - Telescope technology Chania, Greece

${ }^{1}$ Fraunhofer IOF, Jena, Germany

2 Holota Optics, Neuhaus (Schliersee), Germany

${ }^{3}$ DLR, Köln, Germany

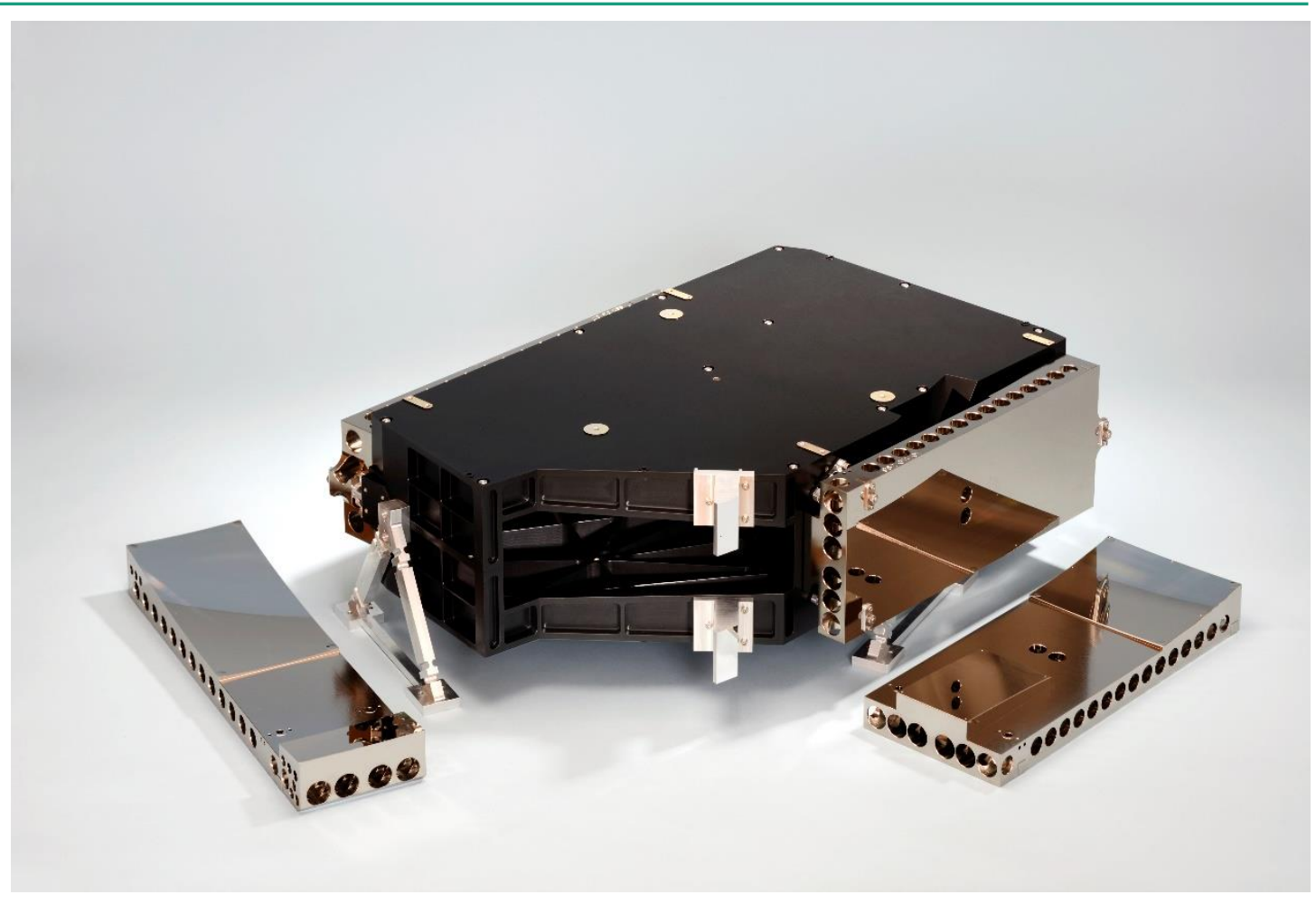




\section{Metal optics for space instrumentation}

\section{Advantages for IR applications}

- Aluminum is the basis for reflective optics and mechanical structures in the IR

- Small to mid-sized space and Earth based optical instruments

- Easy to manufacture, flexible in shape

- Integration of functionalities (mounting, metrology)

- Diamond machining achieves tolerances on single figure and roughness

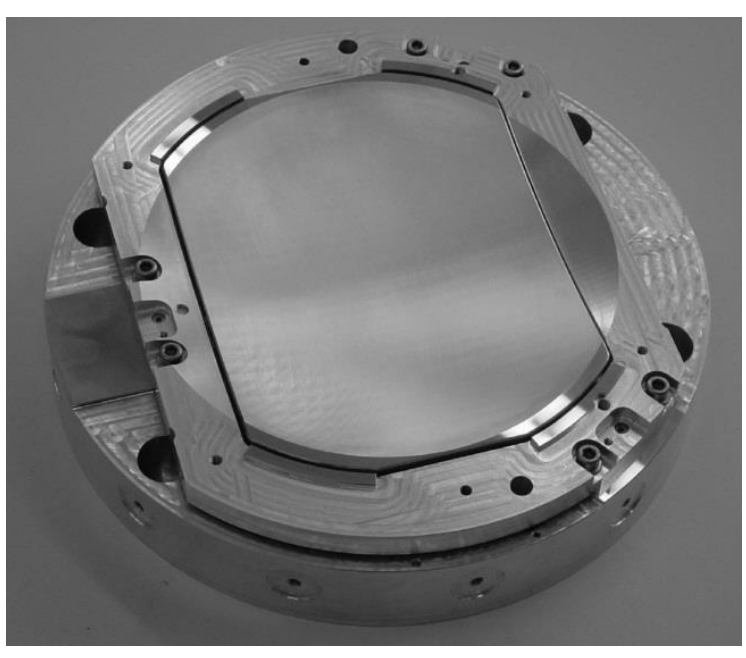

MIRI spectrometer optics on JWST [1]

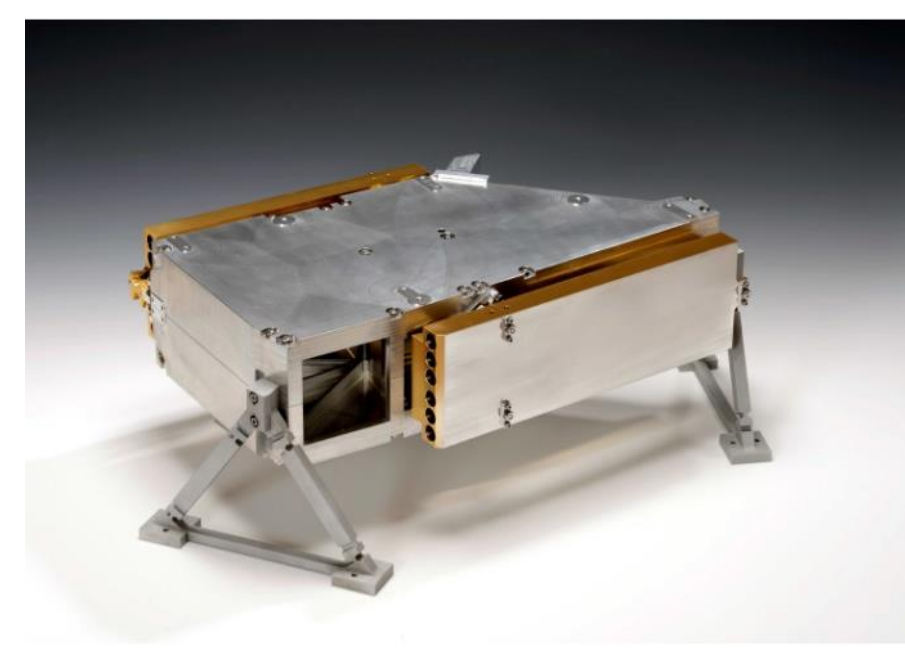

Snap-together assembly for PREMIER [2]

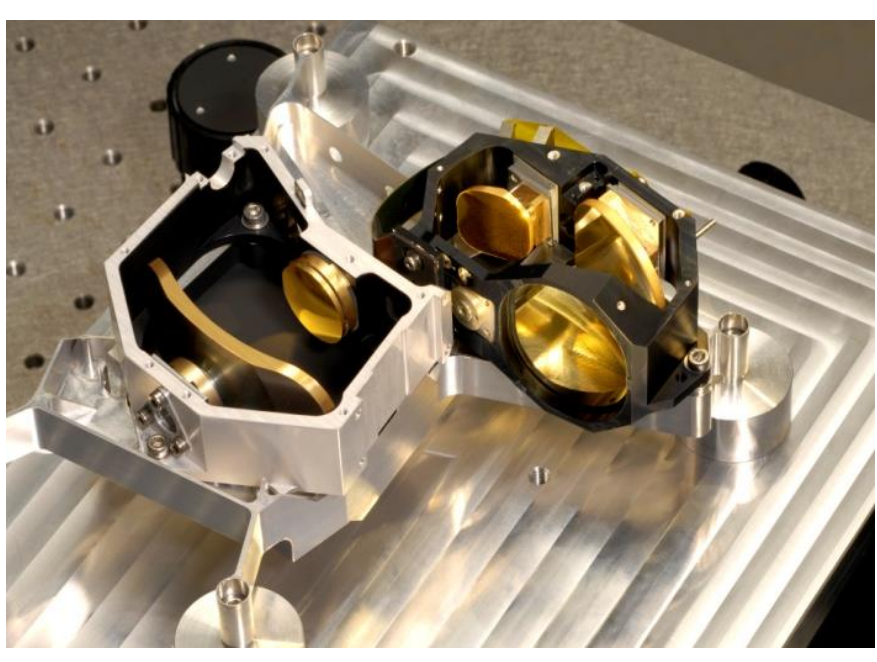

MERTIS on BepiColombo [3]

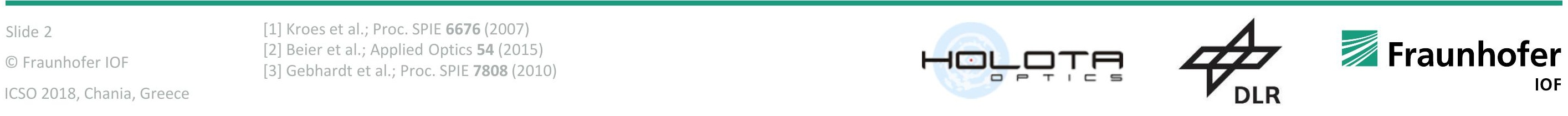




\section{Technology project „VIS-TEL“}

\section{Transfer to UV and VIS applications}

- VIS applications naturally put increased challenges on the optical instrumentation

" „System related“ $\rightarrow$ alignment budget, component quality, etc.

" „Technology related“ $\rightarrow$ materials, process chain for fabrication and test

- Trends towards non-rotationally symmetric optics / freeform optics

- Assembly critical (DOF's, tolerances, etc.)

- Referencing throughout manufacturing / testing essential

\section{Goals for "VIS-TEL“"}

$>$ Development of a freeform-capable process chain for VIS metal optics

$>$ Transfer of smart integration approach to VIS applications

$>$ Establish design rules for fabrication and test of freeform optics 


\section{„VIS-TEL“ freeform telescope}

\section{Optical design}

- Afocal anamorphic imaging telescope

- Suitable as front optics, unobscured off-axis design with four freeform mirrors

- Diffraction limited at $\lambda=632.8 \mathrm{~nm}$ over most of the central FOV

- Average RMS wave aberration 0.095 $\lambda$
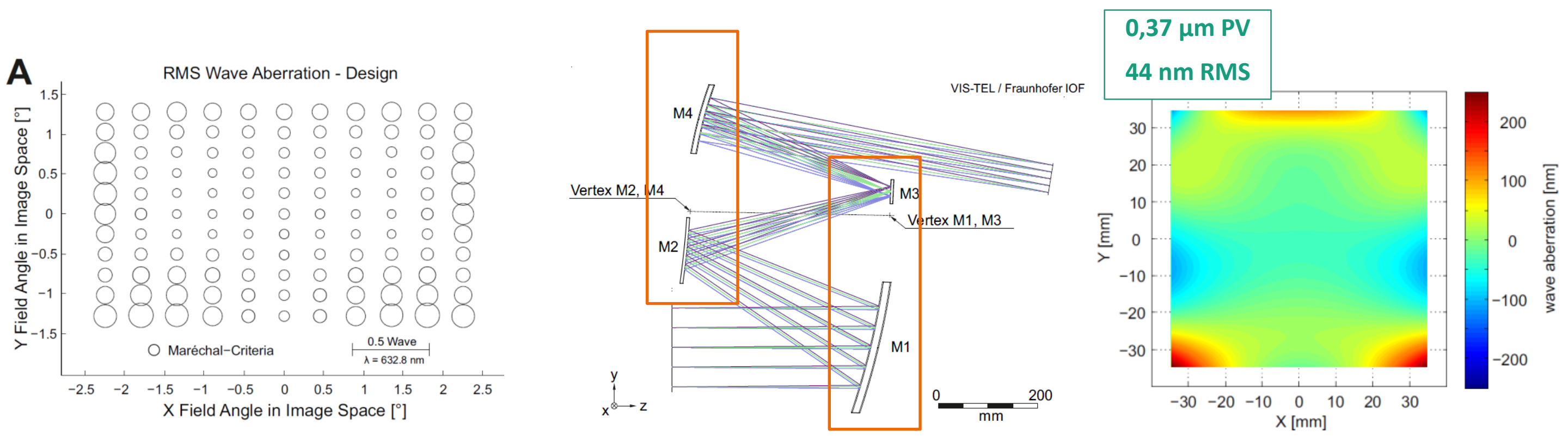

RMS wave aberration vs. FOV

Optical design - YZ plane

Wave aberration in central field 


\section{„VIS-TEL“ freeform telescope}

\section{Mechanical design and integration approach}

- Modular design approach

- Combined manufacturing of M1M3 and M2M4

- Mechanical frame made of two symmetric shells with diamond machined interfaces

- Reduction of adjustable DOF's during system integration from 24 to 3

M1M3

\begin{tabular}{|c|c|}
\hline DOF & Mov \\
\hline TX & Hold \\
\hline TY & Hold \\
\hline TZ & Fixed \\
\hline RX & Fixed \\
\hline RY & Fixed \\
\hline RZ & Hold \\
\hline
\end{tabular}
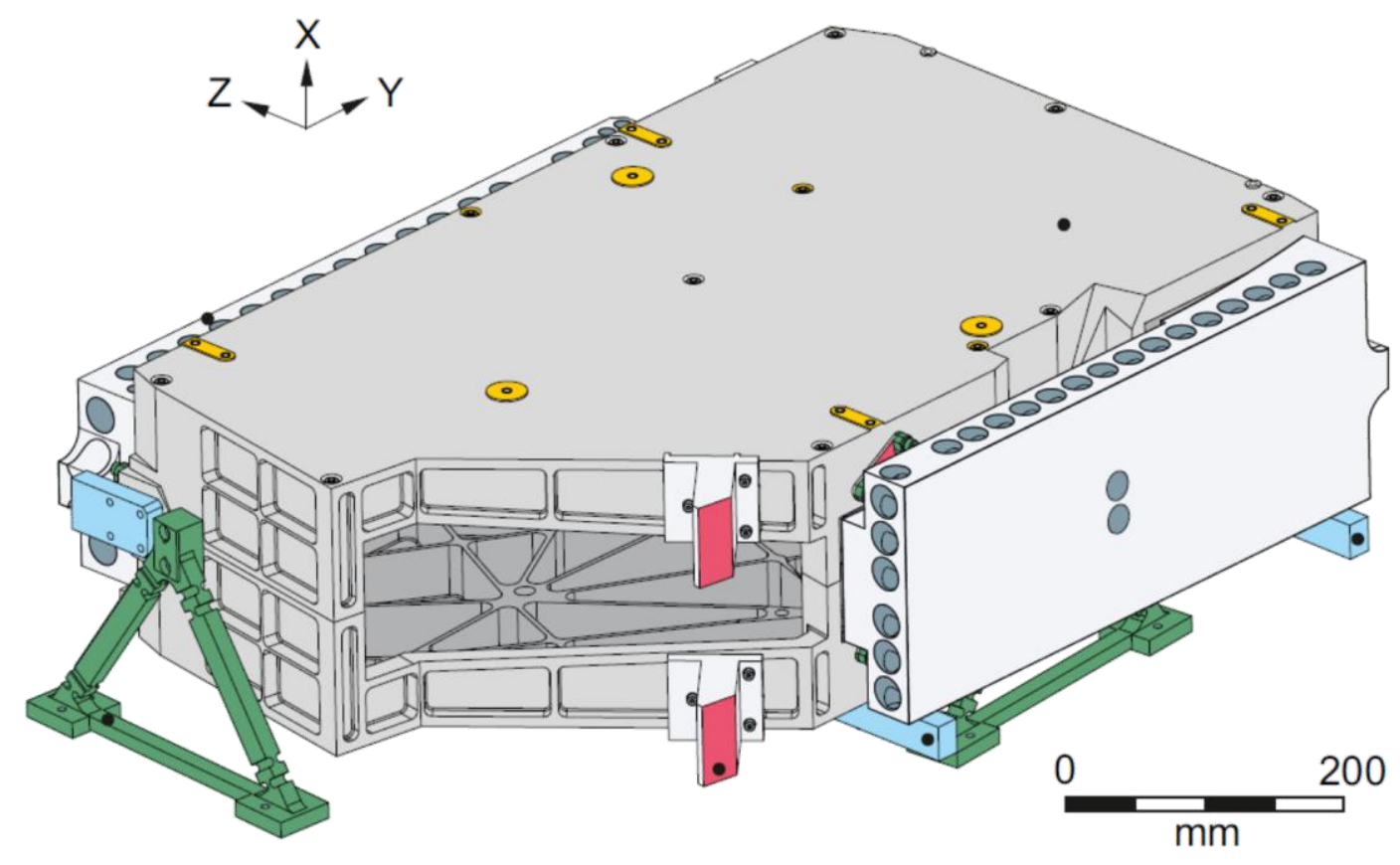

M2M4

\begin{tabular}{|c|c|}
\hline DOF & Mov \\
\hline TX & Open \\
\hline TY & Open \\
\hline TZ & Fixed \\
\hline RX & Fixed \\
\hline RY & Fixed \\
\hline RZ & Open \\
\hline
\end{tabular}




\section{„VIS-TEL“ freeform telescope}

Manufacturing and testing

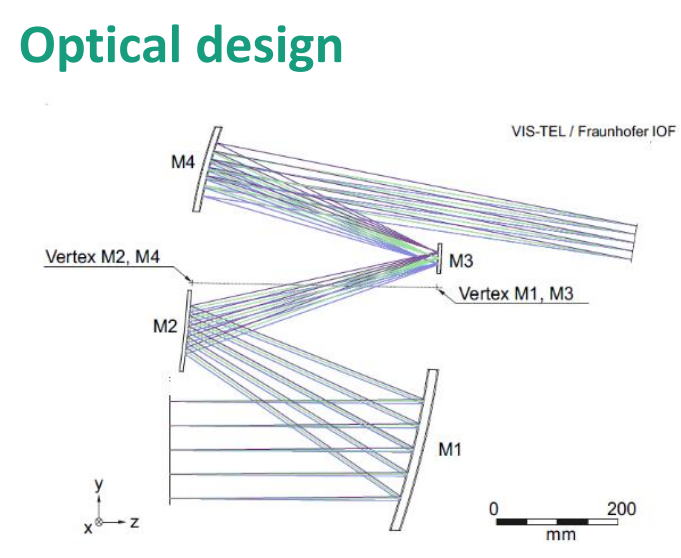

Mechanical design

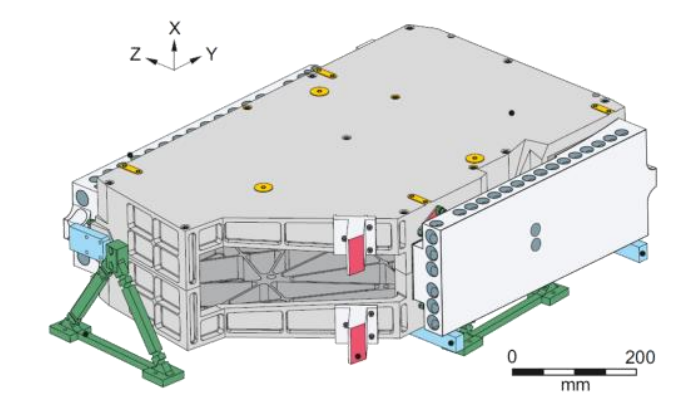

Design phase
Diamond machining

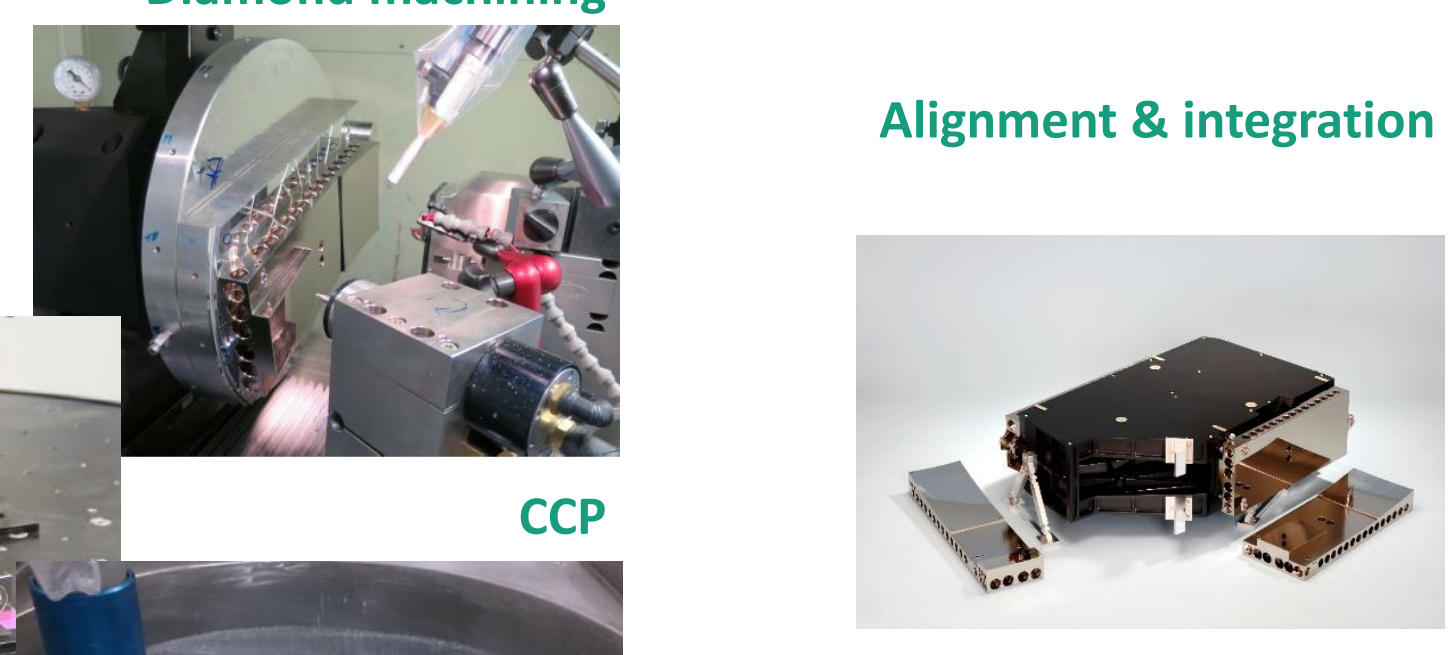

Optical system test

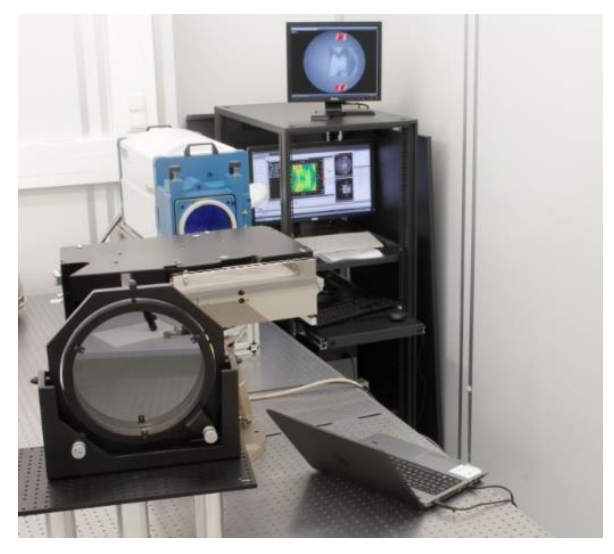

System integration

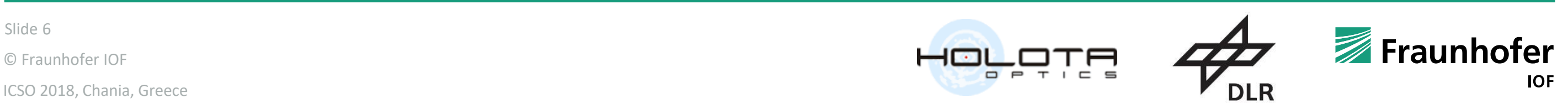




\section{„VIS-TEL“ freeform telescope}

Integration of diamond machined mirrors

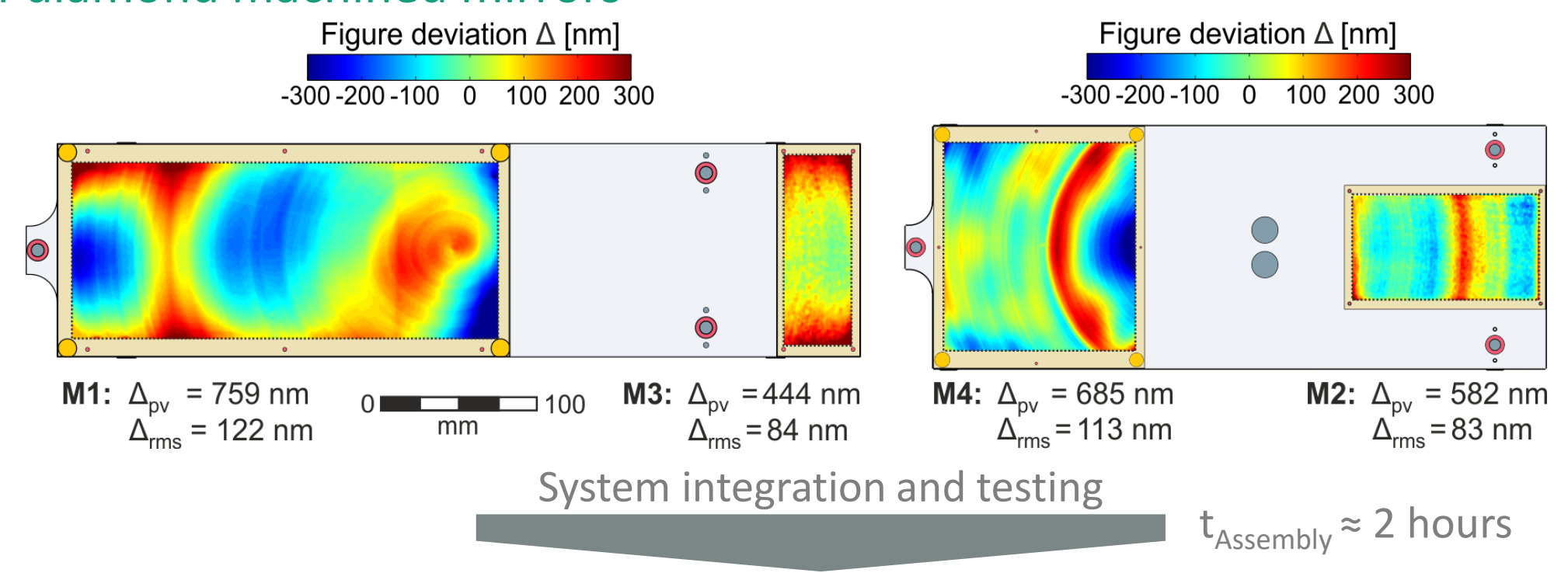

- Direct measurable wavefront

- Very good correlation between mirror surface errors and system wavefront

- Imaging quality limited by single mirror surface form
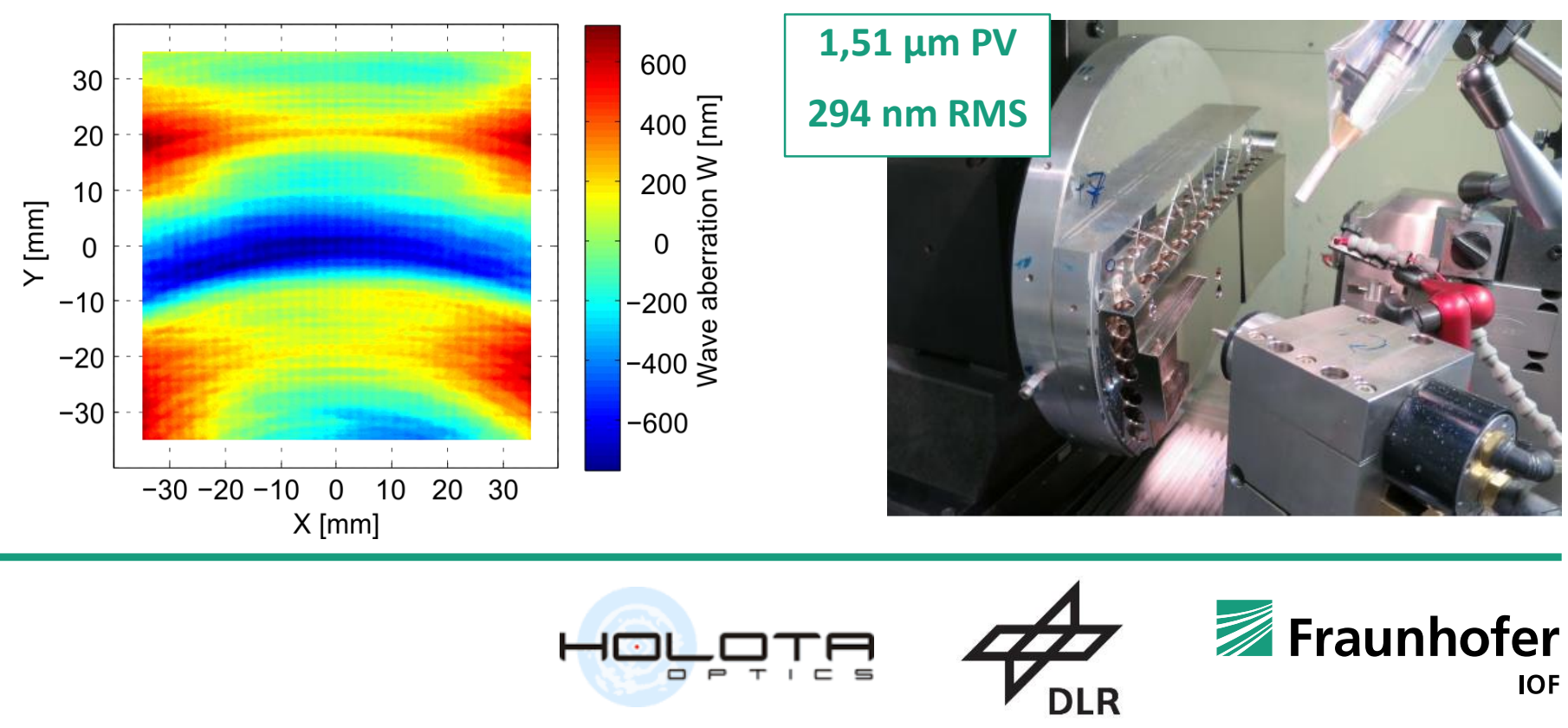


\section{„VIS-TEL“ freeform telescope}

Integration of MRF corrected mirrors

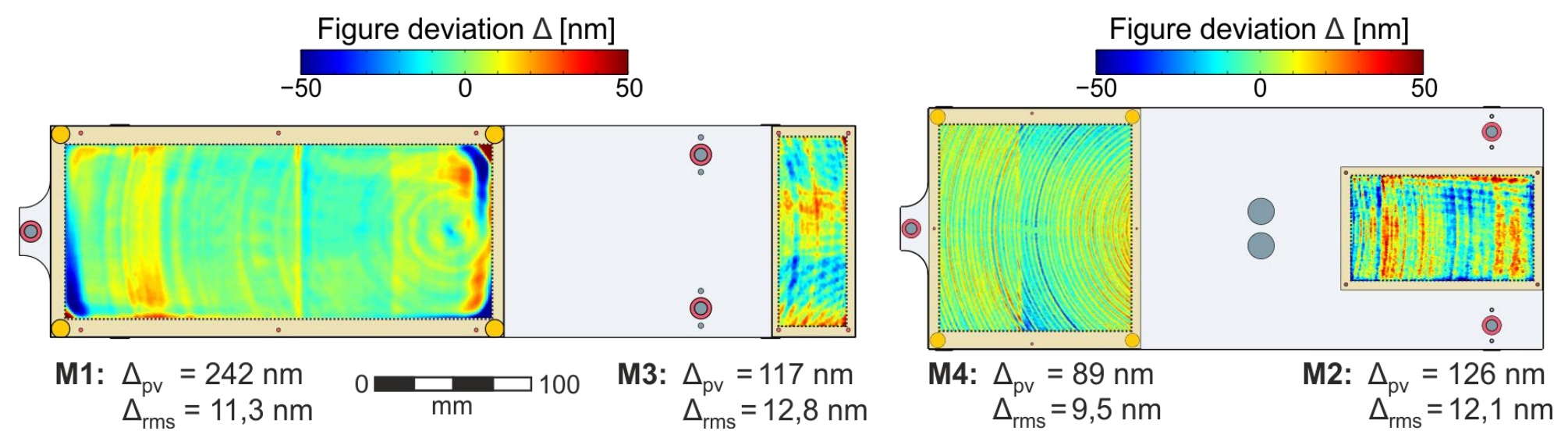

System integration and testing

- Deterministic improvement of low-order terms

- Telescope quality limited by midspatial frequencies and low-order defocus term

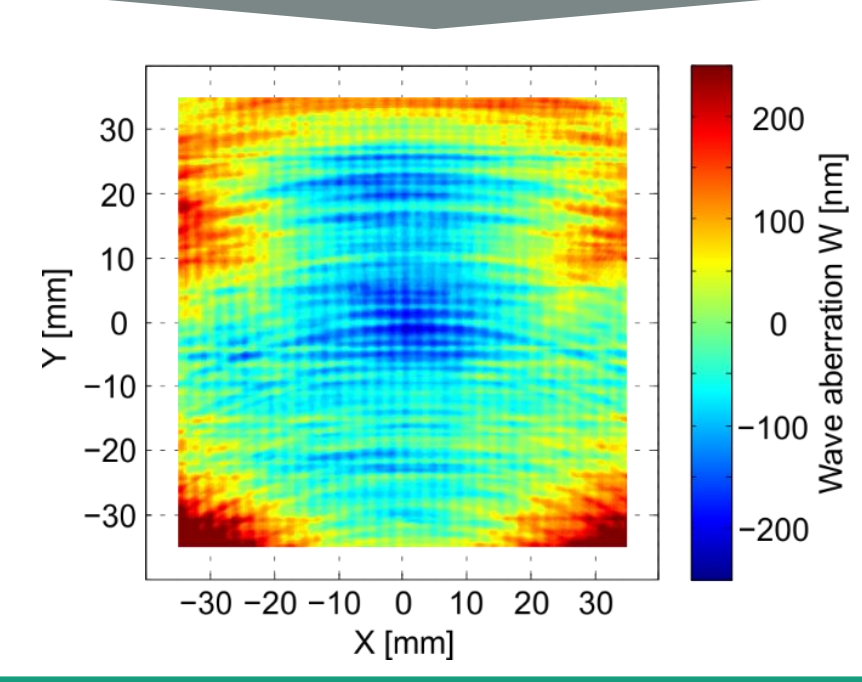

$\mathrm{t}_{\text {Assembly }} \approx 2$ hours

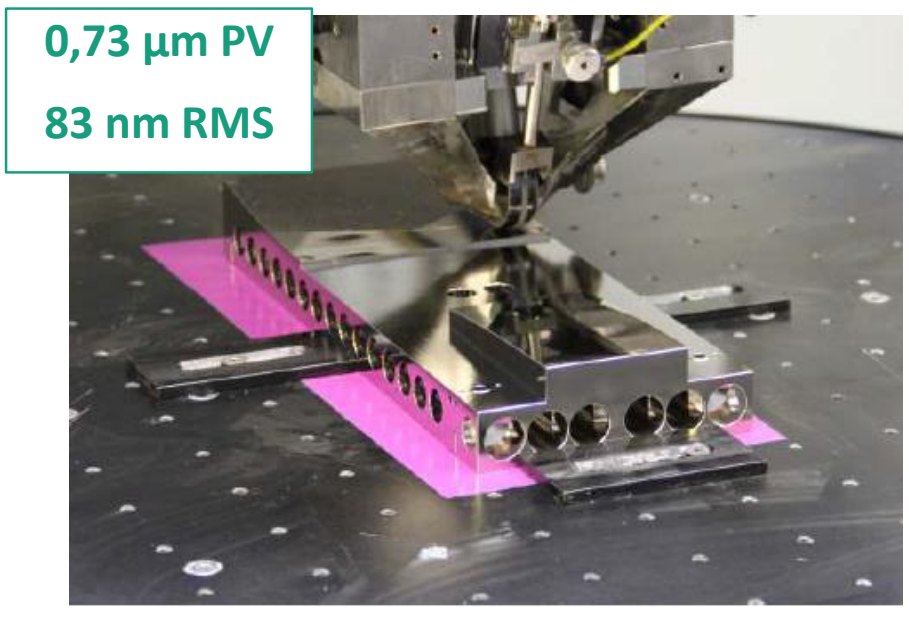




\section{„VIS-TEL“ freeform telescope}

Integration of CCP smoothed and MRF corrected mirrors
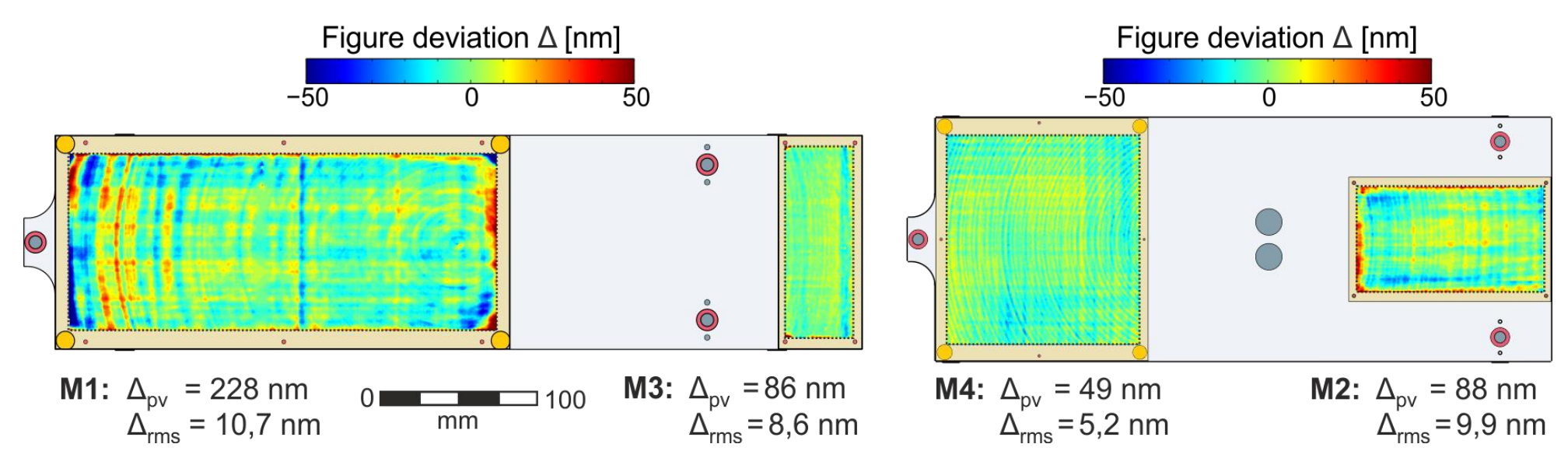

System integration and testing

$$
\mathrm{t}_{\text {Assembly }} \approx 2 \text { hours }
$$

- Smoothing of mid-spatial content

- Increased low-order defocus because of necessary material removal on all mirror surfaces
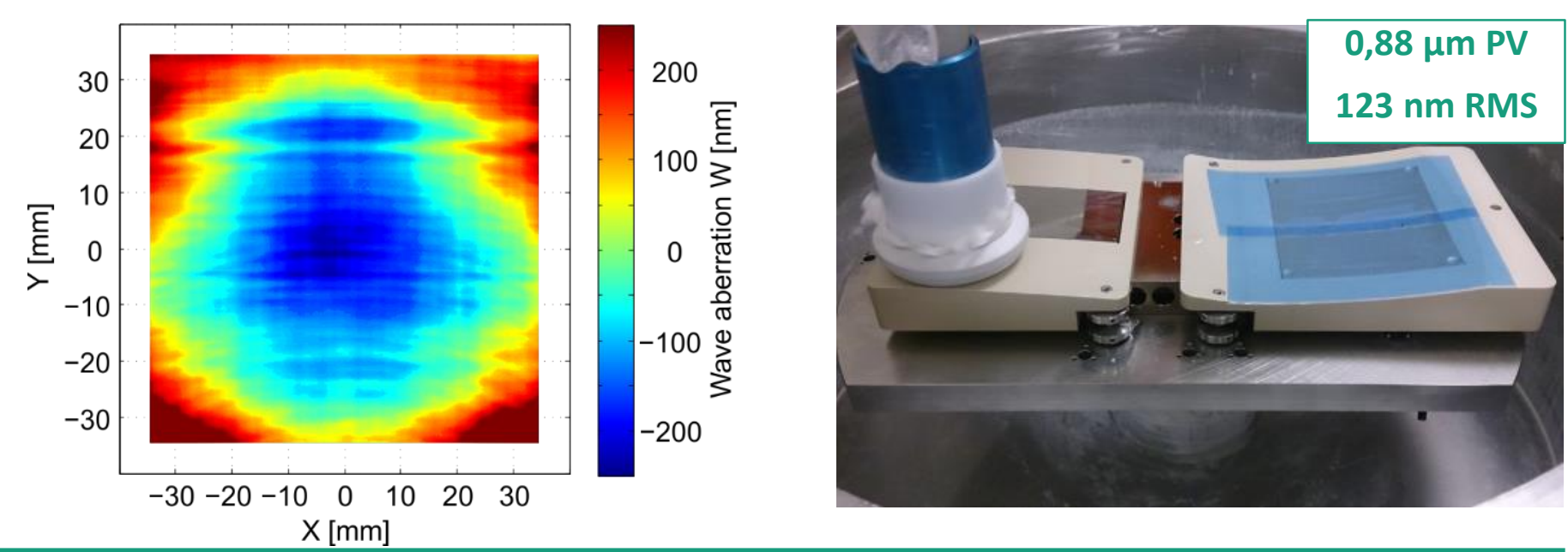


\section{„VIS-TEL“ freeform telescope}

Mechanical design and integration approach

- Modular design approach

- Combined manufacturing of M1M3 and M2M4

- Mechanical frame made of two symmetric shells with diamond machined interfaces

- Reduction of adjustable DOF's during system integration from 24 to 3

M1M3

\begin{tabular}{|c|c|}
\hline DOF & Mov \\
\hline TX & Hold \\
\hline TY & Hold \\
\hline TZ & Fixed \\
\hline RX & Fixed \\
\hline RY & Fixed \\
\hline RZ & Hold \\
\hline
\end{tabular}

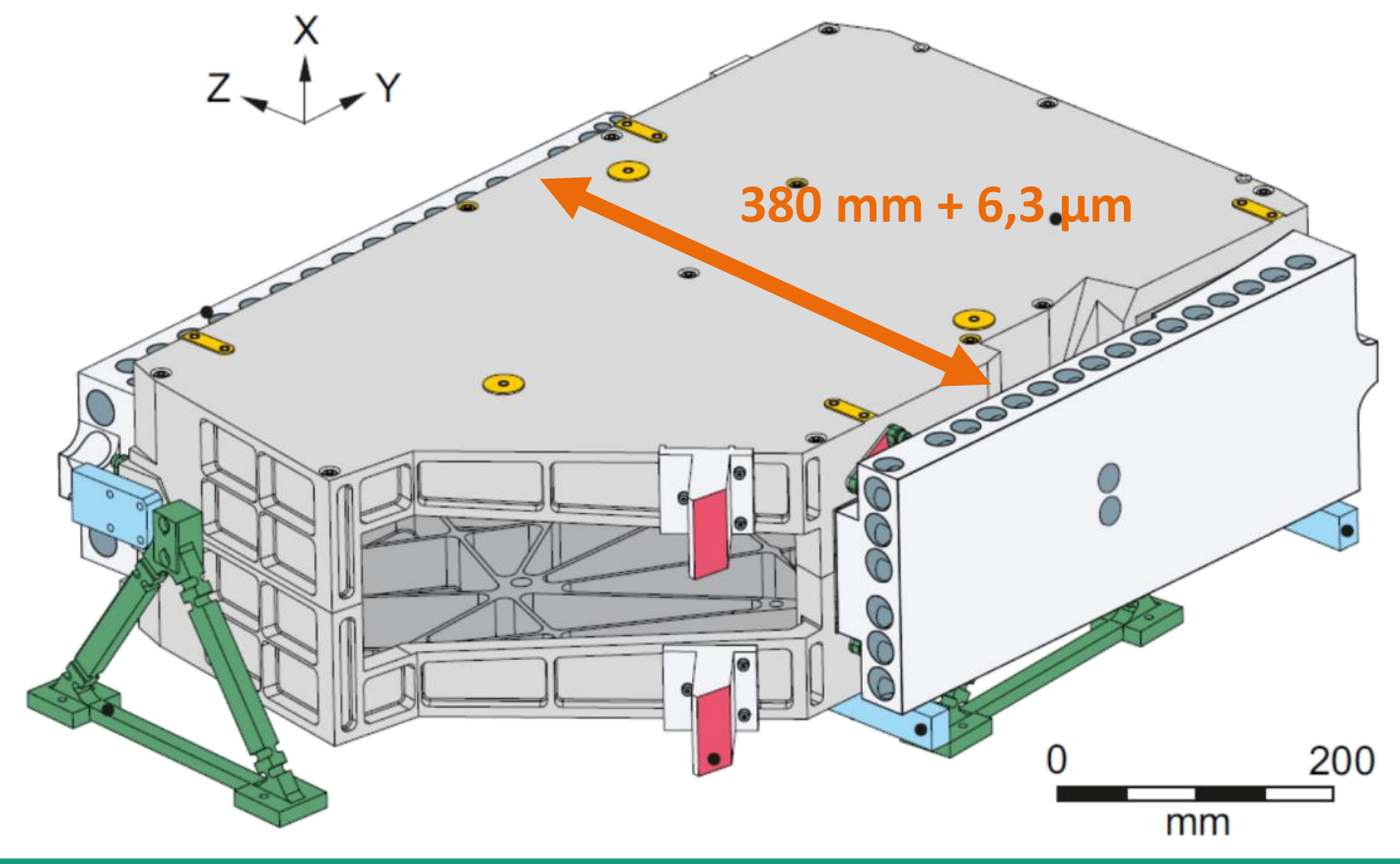

M2M4

\begin{tabular}{|c|c|}
\hline DOF & Mov \\
\hline TX & Open \\
\hline TY & Open \\
\hline TZ & Fixed \\
\hline RX & Fixed \\
\hline RY & Fixed \\
\hline RZ & Open \\
\hline
\end{tabular}




\section{Static wavefront compensation}

Fabrication of a „perfectly bad“ optical surface

- Experimental measurement of assembled telescope in 121 field points

- Import into optical ray trace software

- Calculation of a system compensating mirror surface

$>$ Field constant defocus $\rightarrow$ selection of M4 as compensator

\section{Manufactured compensator on M4}

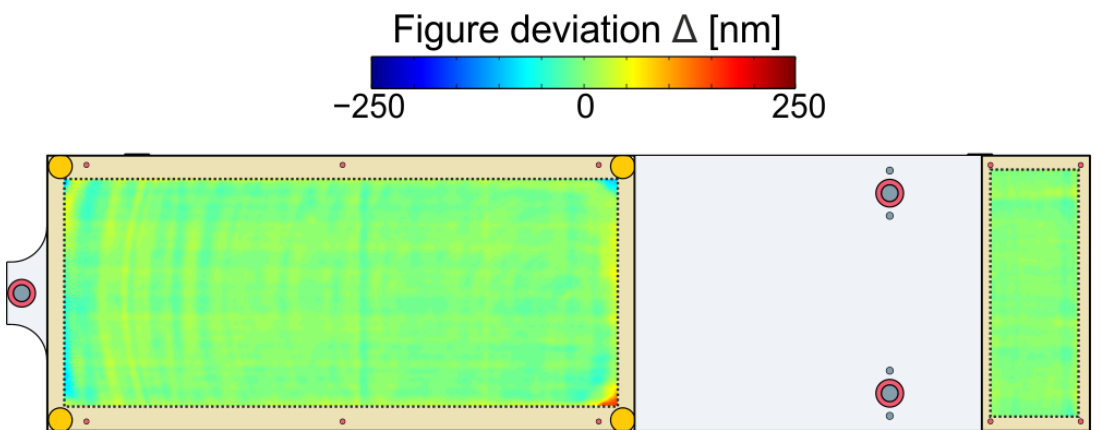

M1: $\Delta_{\mathrm{pv}}=228 \mathrm{~nm}$ $\Delta_{\mathrm{rms}}=10,7 \mathrm{~nm}$

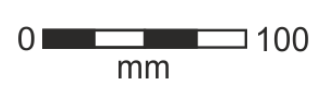

M3: $\Delta_{\mathrm{pv}}=86 \mathrm{~nm}$ $\Delta_{\mathrm{rms}}=8,6 \mathrm{~nm}$

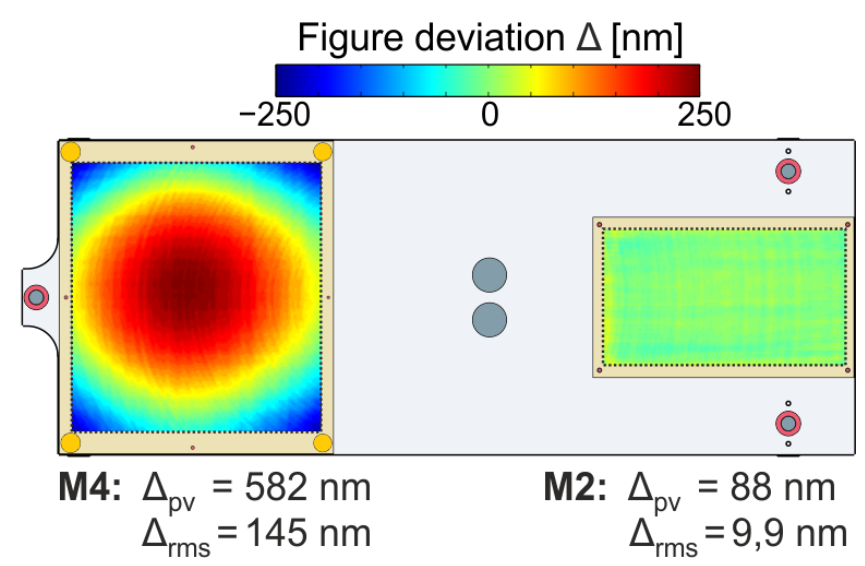

Optical system test over FOV

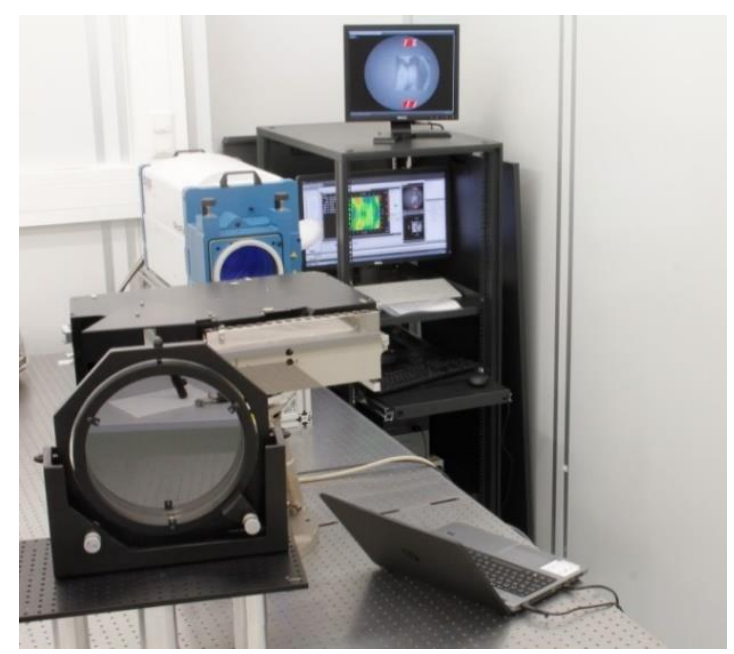

Full field display

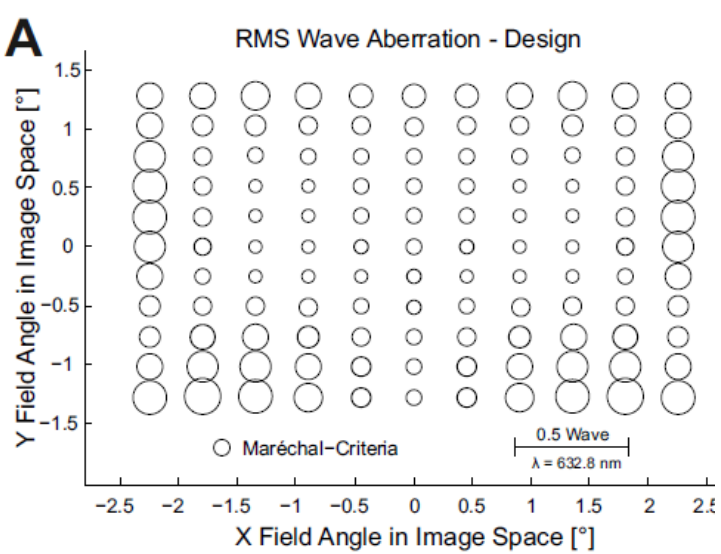

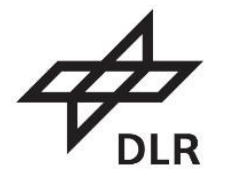




\section{Static wavefront compensation}

Integration of the mirror modules with corrector surface

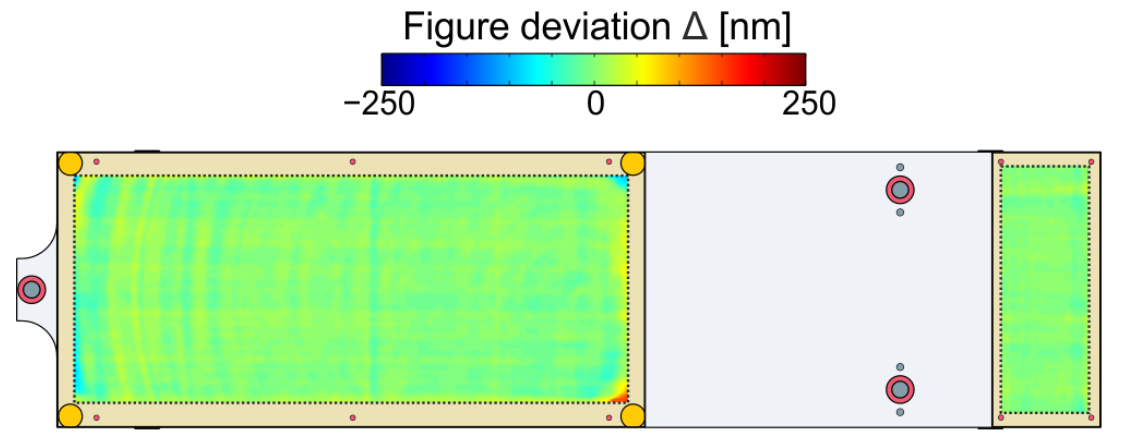

M1: $\Delta_{\mathrm{pv}}=228 \mathrm{~nm}$

$\Delta_{\mathrm{rms}}=10,7 \mathrm{~nm}$

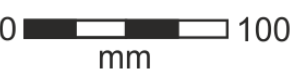

M3: $\begin{aligned} \Delta_{\mathrm{pv}} & =86 \mathrm{~nm} \\ \Delta_{\mathrm{rms}} & =8,6 \mathrm{~nm}\end{aligned}$

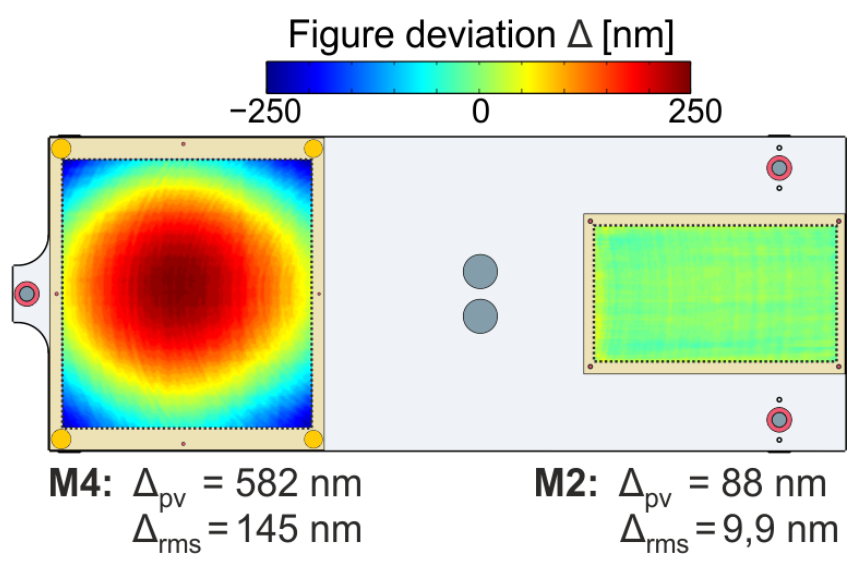

System integration and testing

- Excellent agreement to optical design

- Smart integration approach verified for diffraction limited VIS telescope

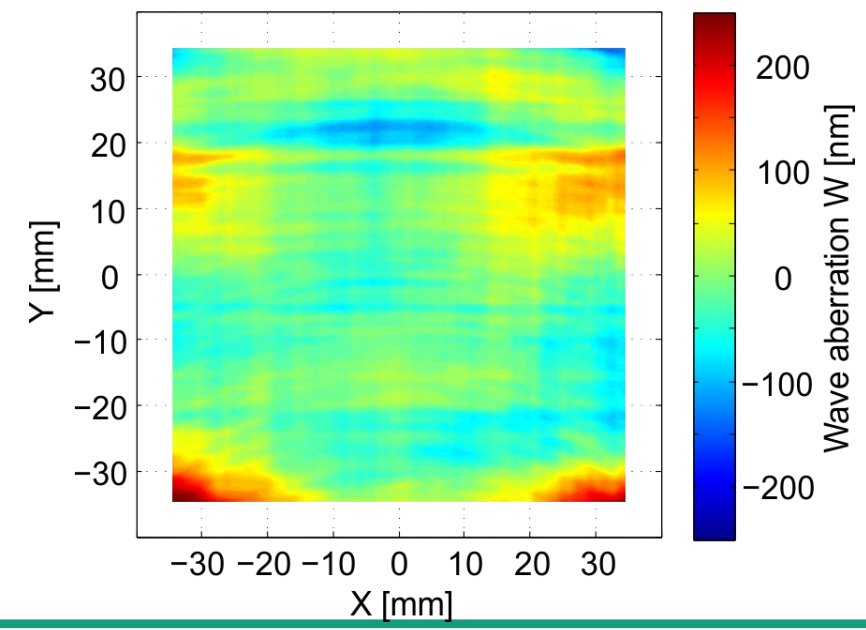

$\mathrm{t}_{\mathrm{Assembly}} \approx 30 \mathrm{mins}$ 


\section{„VIS-TEL“ freeform telescope}

Comparison of system quality at different manufacturing levels
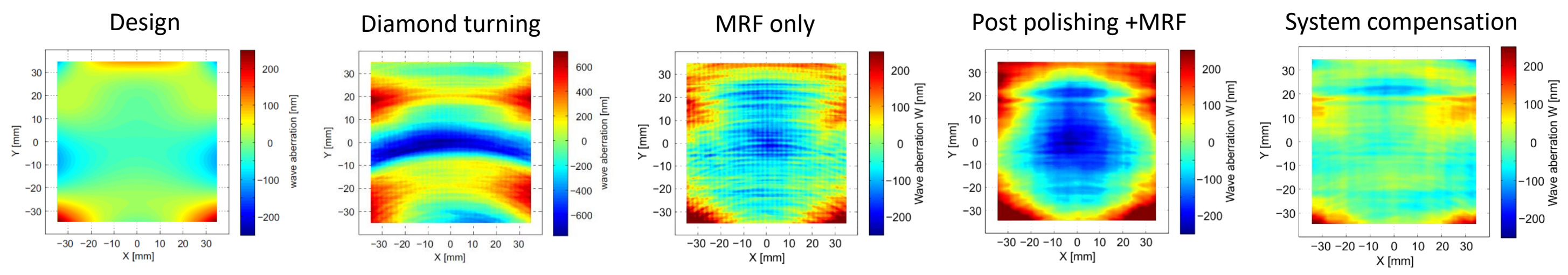

- 377 nm p.-v.

- 1,51 um p.-v.

- 732 nm p.-v.

- 880 nm p.-v.

- 830 nm p.-v.

- $294 \mathrm{~nm}$ rms

- $83 \mathrm{~nm}$ rms

- $123 \mathrm{~nm} \mathrm{rms}$

- 45,3 nm rms

- Very deterministic system development

- Influence of each freeform surface during every manufacturing step easily understood

- Simple and smart integration approach $\rightarrow$ reproducibility!

- Alignment of diffraction limited freeform telescope within hours possible! 


\section{From technology development to space instrumentation...}

\section{Development and realization of the DESIS imaging spectrometer}

- Development of the optical part of the hyperspectral imaging instrument DESIS at IOF

- TMA and spectrometer based on easy alignment technology

- AlSi40 + NiP for mirror and curved grating manufacturing

- Successfull launch to ISS, first promising pictures

DESIS scan over Dubai, dlr.de , 02.10.2018
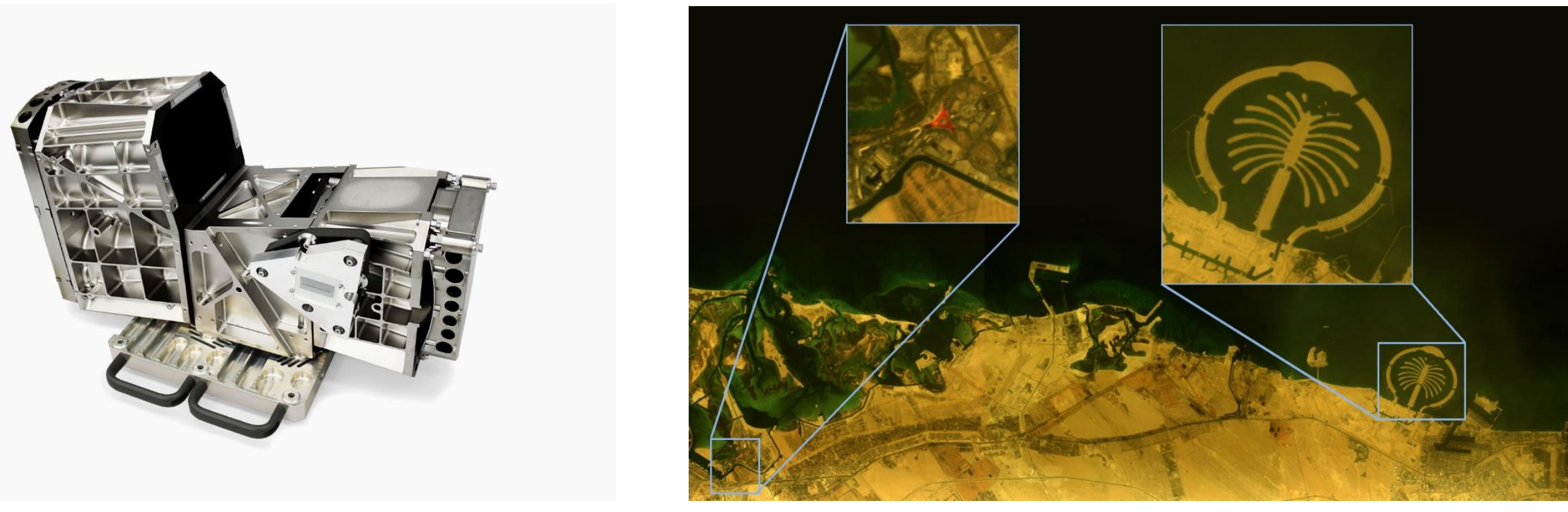


\section{Optical instrumentation technology at IOF}

\section{Summary and outlook}

- Realization of freeform mirror telescopes for applications UV - VIS - IR

- Freeform fabrication: SPDT, MRF, CCP, ...

- Freeform testing: $\mathrm{CGH}$, stitching interferometry, high-accuracy profilometry, ...

- Easy system integration approaches

- Surface modularization

- Ultra-precise manufacturing of interfaces and references

- Transfer of technology to scientific instrumentation $\rightarrow$ DESIS

- Further development needed (strong freeforms, grating technology, etc.) 


\section{Acknowledgements}

\section{Technology project „VIS-TEL“}

The fundamental research was funded

by the DLR in the project VISTEL, Grant \#50EE1224.

We acknowledge Wolfgang and Karin Holota from Holota Optics for the development of the optical design and their support within the project.

All colleagues from the group precision systems at Fraunhofer IOF are acknowledged for their support.
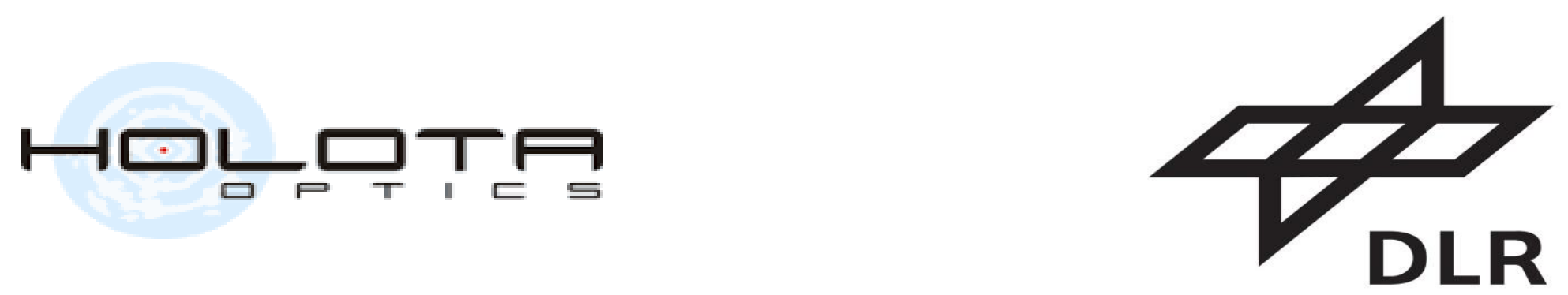


\section{Metal mirror based VIS freeform telescope with smart alignment approach}

\section{Matthias Beier $^{1 *}{ }^{*}$ Stefan Risse ${ }^{1}$, Wolfgang Holota ${ }^{2}$, Christoph Straif $^{3}$,Sebastian Fischer ${ }^{3}$,}

ICSO 2018, Session 4b - Telescope technology Chania, Greece

${ }^{1}$ Fraunhofer IOF, Jena, Germany

2 Holota Optics, Neuhaus (Schliersee), Germany

${ }^{3}$ DLR, Köln, Germany

* matthias.beier@iof.fraunhofer.de
Thank you for your attention!

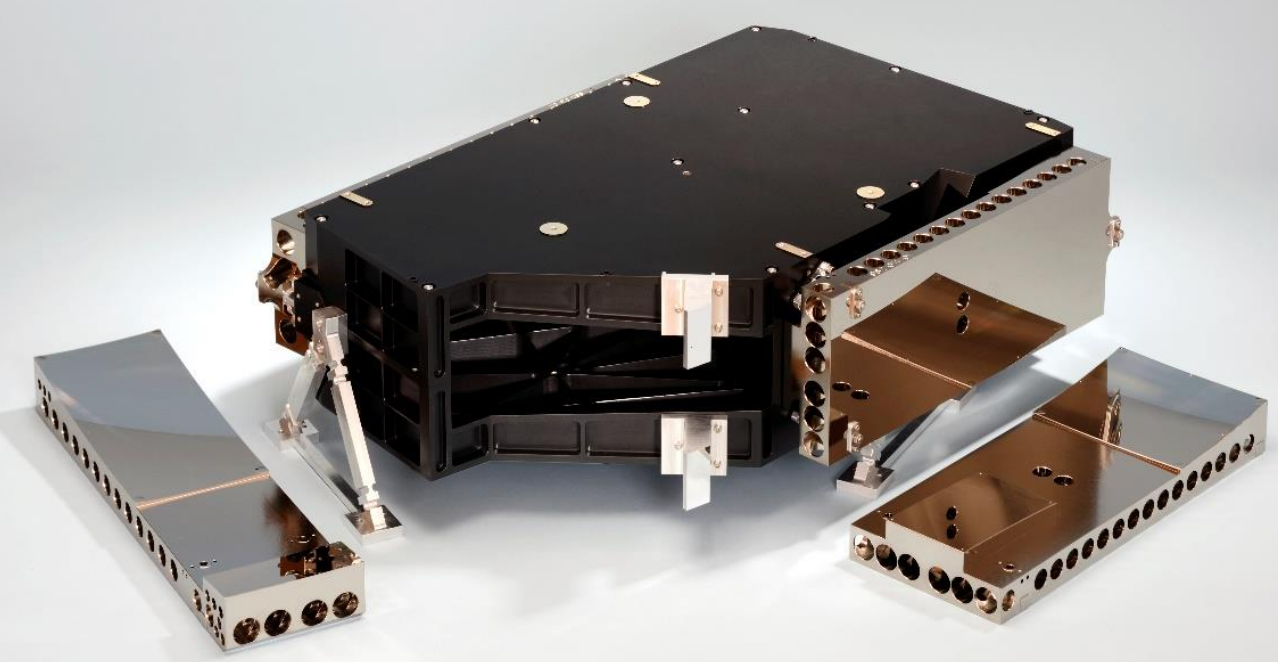

